\title{
Trends of overweight and obesity among preschool children from 2013 to 2018: A cross-sectional study in Rhine-Neckar County and the City of Heidelberg, Germany
}

\author{
Weina Liu \\ Heidelberg University \\ Peter Dambach \\ Heidelberg University \\ Mike Z. He \\ Icahn School of Medicine at Mount Sinai \\ Rainer Schwertz \\ Public Health Office of Rhein-Neckar-Kreis \\ Simiao Chen ( $\nabla$ simiao.chen@uni-heidelberg.de ) \\ Heidelberg University \\ Fengyun Yu \\ Heidelberg University \\ Michael Marx \\ Heidelberg University
}

\section{Research Article}

Keywords: Trends of overweight and obesity, preschool children, cross-sectional study

Posted Date: December 13th, 2021

DOI: https://doi.org/10.21203/rs.3.rs-1070446/v1

License: (c) (i) This work is licensed under a Creative Commons Attribution 4.0 International License.

Read Full License 


\section{Abstract}

\section{Background}

Early childhood overweight and obesity is a growing public health concern worldwide. Few recent studies have addressed how time trends varied by sociodemographic characteristics at the regional level using large and high-quality data. This study aims to determine how time trends vary in the prevalence of early childhood overweight and obesity by age, gender, and migration background at the regional level.

\section{Methods}

We described the distribution change in the BMI with a Kernel-density curve, and evaluated the trends of overweight and obesity by age, gender, and migration background using logistic regression.

Results

Mean BMI and the prevalence of overweight and obesity increased among preschool children aged 4-6 years in the Rhine-Neckar County and the City of Heidelberg. After adjusting for age, gender, and migration background, trends in the prevelance of overweight significantly increased only among male children in the age 5 year group with migration background $(P<0.05)$, and an upward trend of obesity was observed only among male children in the age 5 year group and female children in the age 6 year group with migration background $(P<0.05)$.

Conclusions

BMI distribution as well as general prevalence of overweight and obesity are still increasing among preschool children. Children with migration backgrounds, particularly male children in the age 5 year groups and female children in the age 6 year group should be prioritized. More prevention policies should be targeted towards vulnerable groups.

\section{Introduction}

Early childhood is a critical stage of life, marked by significant physical and neural development. Specially, early childhood overweight and obesity is a growing public health concern worldwide. Childhood overweight and obesity not only leads to adverse consequences including physical and mental health disorders [1, 2], but also results in impacts on the later adulthood life, such as an increased risk of diabetes, osteoarticular diseases, cardiovascular diseases, and cancer[2]. The pooled prevalence estimates of overweight in European children (aged 2-7 years) was $17.9 \%$ and obesity was $5.3 \%$ from 2006 to 2016[3]. According to the results of the German Health Interview and Examination Survey for Children and Adolescents, the prevalence of overweight among preschool children in Germany was $10.8 \%$ for female children and $7.3 \%$ for male children, and the prevalence of obesity was $3.2 \%$ for female children and $1.0 \%$ for male children between 2014 and 2017[4]. 
Existing studies show that the trend of overweight and obesity in preschool children are changing. A study performed in Bavaria showed an increasing trend from 1982 to 1997[5]. Another investigation covering all of Germany conducted during 1991 to 2000 also indicated the same trend[6]. In comparison, the trend was decreasing in 16 German federal states from 2004 to 2008[7]. A similar decreasing trend was also observed in the results of the German Health Interview and Examination Survey for Children and Adolescents between 2014 and 2017[4]. Few existing studies have updated how time trends varied by sociodemographic characteristics at regional level using large and high-quality sample. This study aims to explore how the prevalence of overweight and obesity during early childhood vary by age, gender, and migration background at the regional level over time by means of a large dataset from the School Entry Health Examination (SEHE), which includes all preschool children in the Rhine-Neckar County and the City of Heidelberg, Germany from 2013 to 2018.[8] This study may provide evidence for local health policymakers at regional levels to implement programs for primary prevention of obesity.

\section{Methods}

\subsection{Data sources and study design}

According to the laws and regulations in Baden-Württemberg $[9,10][11]$, all preschool children in the state were examined annually by the Public Health Service before entering the new school year. From 2013 to $2018,37,858$ children from 454 kindergartens of 54 district towns and municipalities participated in the SEHE. We conduct a cross-sectional study with data from SEHE during this period, in order to describe how the prevalence of overweight and obesity changed by age, gender and migration background. All children's data were anonymized before analyses.

\subsection{Measurements and Covariates}

The generated data include measurements of height and weight and general sociodemographic information (age, gender, and migration background). Children were required to wear light clothes and to take off shoes. Body height was accurate to the nearest $1 \mathrm{~cm}$, and body weight was accurate to the nearest 100g. BMI was classified as underweight, normal weight, overweight, and obese according to BMI-for-age Z-scores from the World Health Organization child growth standards [12]. Immigrant background was defined that children with at least one of their parents being born abroad or the language spoken at home is not German or it is German together with another language, which was described by Schenk et al[13].

\subsection{Statistical analysis}

We described the distribution change in BMI between 2013 and 2018 by a Kernel-density curve[14, 15], which is a nonparametric smoothed graph. The trend of overweight and obesity was evaluated with the adjustement of age, gender, and migration background using a logistic regression model with the survey year as independent variable (continuous variable) and the statuses of overweight/obesity as dependent variables (binary variables). Model I was adjusted by age and gender. Model II was adjusted by age, 
gender, immigrant background, and survey year. Statistical significance was set at $P<0.05$. We used the statistical software R (version 3.6.3) to analyze the data.

\section{Results}

\subsection{Characteristics of the study participants}

In this survey, 37,858 children aged 4 to 6 years old were enrolled from 2013 to 2018. 33,407 children had valid information, including 17,304 male children and 16,103 female children. The response rate was $88.2 \%$. The percentage of children that had a migration background was $50.8 \%$. The overall prevalence of overweight and obesity was $7.6 \%$ and $2.8 \%$, respectively. The children ages 4,5 , and 6 accounted for $12.2 \%, 75.0 \%$ and $12.8 \%$ of the population respectively. The baseline characteristics of the study population are shown in Table 1. 
Table 1

Baseline characteristics of preschool children in Rhine-Neckar County and the City of Heidelberg

\begin{tabular}{|c|c|c|c|}
\hline Characteristic & & Number & Percentage (\%) \\
\hline \multirow[t]{7}{*}{ Survey Year } & 2013 & 5665 & 17.0 \\
\hline & 2014 & 5619 & 16.8 \\
\hline & 2015 & 4557 & 13.6 \\
\hline & 2016 & 5612 & 16.8 \\
\hline & 2017 & 5956 & 17.8 \\
\hline & 2018 & 5998 & 18.0 \\
\hline & Total & 33407 & 100 \\
\hline \multirow[t]{2}{*}{ Gender } & Male children & 17304 & 51.8 \\
\hline & Female children & 16103 & 48.2 \\
\hline \multirow[t]{3}{*}{ Age } & 4 & 4062 & 12.2 \\
\hline & 5 & 25078 & 75.0 \\
\hline & 6 & 4267 & 12.8 \\
\hline \multirow[t]{2}{*}{ Migration background } & Non-migrant & 16436 & 49.2 \\
\hline & Migrant & 16971 & 50.8 \\
\hline \multicolumn{4}{|l|}{ Nutrition status } \\
\hline & Normal & 29605 & 88.6 \\
\hline & Underweight & 357 & 1.1 \\
\hline & Overweight & 2525 & 7.6 \\
\hline & Obesity & 920 & 2.8 \\
\hline
\end{tabular}

\subsection{Secular trend in BMI}

From 2013 to 2018, mean BMI increased from 15.5 to $15.7 \mathrm{~kg} / \mathrm{m}^{2}$ for male children, and increased from 15.4 to $15.6 \mathrm{~kg} / \mathrm{m}^{2}$ for female children. Similar upward trends were observed among almost all preschool children except for male children aged 4 years (Table S1). The BMI distribution curves for male children and female children all shifted to the right from 2013 to 2018, except for male children of aged 4 years (Figure 1).

Figure 1. Distribution change of body mass index among male (a) and female (b) preschool children.

\subsection{Trends of overweight}


From 2013 to 2018, the prevalence of overweight (7.2\% vs 6.7\%) in preschool children increased significantly in Rhine-Neckar County and the City of Heidelberg (Figure 2(a)), especially for the 5-year old age group $(P<0.05 ;$ Table S2). As shown in Table S3 and Table S4, the prevalence of overweight increased from $7.1-8.2 \%$ for male children, while showing no upward trend for female children $(P>0.05)$. After adjusting by age and gender (Figure 2(b)), the prevalence of overweight for male children increased from $6.5-8.0 \%$ among 5-year olds, while for female children it did not significantly increase across all age groups during this period ( $P>0.05 ;$ Table S4; Figure 2(d)). After adjusting by age, gender, and migration background, for male children, the prevalence of overweight increased from 5.2-6.7\% among 5-year olds with migration background $(P<0.05$;Table S3; Figure 2(f)), while no significant changes were observed for female children $(P>0.05$;Table $S 4$; Figure $2(f) \&(h))$ across all age groups, irrespective of migration background.

Figure 2. The trend of overweight and obesity from 2013 to 2018

a - The general trend

b,c- The trend adjusted by sex

d,e- The trend adjusted by sex,age

$\mathrm{f}, \mathrm{g}, \mathrm{h}, \mathrm{i}-\mathrm{T}$ - the trend adjusted by sex,age and migration background

\subsection{Trends of obesity}

When comparing with the trend of overweight, the prevalence of obesity $(8.2 \%, 2018$ vs $7.1 \%, 2013)$ also increased significantly across all age groups over the 6-year period $(P<0.05$; Table S5, Figure 2(a)). After adjusting by gender and age, the prevalence of obesity among male children and female children barely changed from 2013 to 2018 ( $P>0.05$; Table S6 and S7, Figure 2(c)); however, it increased among 6-year olds in both gender $(P<0.05$; Table S7 and Table S8, Figure 2(e)). After adjusting by gender, age, and migration background, male children aged 5 years with migration background and female children aged 6 years experienced an increase in the prevalence of obesity $(P<0.05$; Table S7 and S8, Figure 2(g)), whereas a downward trend was observed only for male children aged 4 years $(P<0.05$; Table S7, Figure 2(i)).

\section{Discussion}

This cross-sectional study showed that the BMI distribution and the prevalence of overweight and obesity among preschool children aged 4-6 years in the Rhine-Neckar County and the City of Heidelberg increased between 2013 and 2018. After adjusting for age, gender, and migration background, the significant increasing trend of overweight was only detected among 5-year old male children with migration backgrounds. The upward trend of obesity was observed only for male children aged 5 years and for female children aged 6 years with migration backgrounds. This is the first population-level study that uses a dataset with such a large sample of School Health Entry Examination data to illustrate the time 
trends of overweight and obesity among preschool children in Rhine-Neckar County and the City of Heidelberg.

Our study demonstrated that the BMI distribution was increasing, which was consistent with studies by Jena et al. [16] and Aachen et al. [17]. In recent decades, although the global trend of overweight and obesity among children has been increasing[18], previous studies reported that the prevalence of overweight and obesity among German preschool children showed a downward trend after $2004[5,6$, 19]. However, our study showed an opposite trend. The cause of this phenomenon may be that the trend of overweight and obesity varies widely in federal states[7], and different measurement or assessment methods of obesity[20] were conducted in different regions. Another reason could be that migration background is regarded as a potential health determinant for the prevalence of overweight and obesity[21]; Rhine-Neckar County and the City of Heidelberg belongs to Baden-Württemberg, where the proportion of people with an migrantion background accounted for the top three states in Germany[22]. All of the above factors may lead to an increasing trend in the prevalence of overweight and obesity. Although the German government has emphasized controlling obesity in the National Sustainable Developmental Strategy in 2016 [23], it remains difficult to apply health promotion and prevention measures to young children, especially for preschool children. Decreased energy expenditure or increased energy intake was regarded to be the cause of increasing obesity[24]. Many countries have established recommendations regarding the amount of time children and adolescents should take part in physical activities [25]. Due to the different type of kindergartens and their possible space limitations, it is difficult to quantify the intensity and time of physical exercise available for preschool children. Although one study showed that preschool children were more physically active on forest playgrounds than on traditional playgrounds [26], the forest kindergartens only accounted for a small proportion in RhineNeckar County and the City of Heidelberg. Besides, preschool children usually spend a lot of time with parents, and parenting style greatly affects children's behavior $[27,28]$, including different diet types and use of visual media, which may influence children's weight and/or height. Taken together, our findings indicate that the government should develop and propagate appropriate policy, if possible, adapted to the type of kindergarten, and help parents establish healthy parenting styles.

Although the general prevalence of overweight and obesity in Rhine-Neckar County and the City of Heidelberg showed an upward trend, after adjusting by age, gender, and migration background, the increasing trend of overweight and obesity was only observed among male children aged 5 years with migration backgrounds and female children aged 6 years with migration backgrounds. Migration background has already been regarded as an independent potential risk factor for overweight and obesity in earlier studies [29-32]. One possible explanation could be the parenting style of migrants such as lower education of parents' perception of parenting, sedentary behavior, and unhealthy diet habits [33]. We also found discrepancies in trends of overweight and obesity after adjusting for age, which were similar to previous findings $[4,34,35]$ which found that the prevalence of overweight and obesity increased with age. This disparity may be related to the period of adiposity rebound occurring between 4 and 7 years old $[36,37]$. Previous studies showed that the capacity of infants and young children to control their food intake is affected by feeding pattern and eating control of mothers [38]. When children become more 
autonomous and more in control of their food intake when growing older, their ability to regulate energy balance may be damaged, which could lead to obesity [37]. Targeted intervention projects are warranted for vulnerable groups, especially for children aged 5-6 years, to optimize the preventive measures.

Our study used a large cross-sectional dataset collected between 2013 and 2018 from the successive surveillance of SEHE, which involved all preschool children in Rhine-Neckar County and the City of Heidelberg. Our sample size was representative of the general preschool population of Rhine-Neckar County and the City of Heidelberg and was able to display the secular trend. Moreover, after adjusting by sociodemographic factors, it realistically reflects the trend of overweight and obesity in this area, which could offers formative evidence to regional policy-makers for preventing and controlling the prevalence of overweight and obesity among vulnerable groups.

Our study has several limitations. Firstly, since this study was based on a cross sectional study design, it could not assess temporality. Secondly, the trend we evaluated was adjusted only by age, gender, and migration background, and other sociodemographic factors should be investigated in further research.

\section{Conclusions}

In conclusion, the BMI and trend of overweight and obesity from 2013 to 2018 was increasing in RhineNeckar County and the City of Heidelberg, especially for male children aged 5 years and female children aged 6 years with migration background. These findings may contribute to the development of targeted efforts preventing or alleviating the prevalence of obesity in susceptible groups among preschool children in Germany.

\section{Abbreviations}

SEHE School Entry Health Examination

\section{Declarations}

\section{Ethical approval}

The data that we analysed was deidentified. All experimental protocols were approved by the Ethics Committee of Heidelberg University, and the ethics approval number is S-169/2021. The informed consent is waived for this study by the Ethics Committee of Heidelberg University. All methods were carried out in accordance with relevant guidelines and regulations.

\section{Patient consent for publication}

Our study was a restrospective study and only had access to deidentified data. Patients and/or the public were not involved in the design, or conduct, or reporting, or dissemination plans of this research, so the patient consent for publication was not required. 
Availability of data and materials

The datasets used and/or analysed during the current study are available from the corresponding author on reasonable request.

Competing interests

The authors declare that they have no competing interests.

\section{Funding}

There was no funding supported.

Authors' contributions

WL conceived the idea, RS, AW, JW, collected data, WL analyzed and verified data, WL wrote the first draft, VW, $\mathrm{PD}, \mathrm{MM}$ and $\mathrm{SC}$ collaboratively reviewed the manuscript.

\section{Acknowledgements}

We are grateful to the Public Health Office of Rhein-Neckar-Kreis for using these data. They are not responsible for the analysis or interpretation of these data.

\section{References}

1. Moreno LA, Pigeot I, Ahrens W: Epidemiology of obesity in children and adolescents. Prevalence etiology, Nueva York: Springer 2011:483.

2. Orsi CM, Hale DE, Lynch JL: Pediatric obesity epidemiology. Current opinion in endocrinology, diabetes, and obesity 2011, 18(1):14-22.

3. Garrido-Miguel M, Oliveira A, Cavero-Redondo I, Álvarez-Bueno C, Pozuelo-Carrascosa DP, SorianoCano A, Martínez-Vizcaíno V: Prevalence of Overweight and Obesity among European Preschool Children: A Systematic Review and Meta-Regression by Food Group Consumption. Nutrients 2019, 11(7).

4. Schienkiewitz A, Brettschneider A-K, Damerow S, Schaffrath Rosario A: Overweight and obesity among children and adolescents in Germany. Results of the cross-sectional KiGGS Wave 2 study and trends. 2018.

5. Kalies H, Lenz J, von Kries R: Prevalence of overweight and obesity and trends in body mass index in German pre-school children, 1982-1997. International Journal of Obesity 2002, 26(9):1211-1217.

6. Apfelbacher CJ, Cairns J, Bruckner T, Möhrenschlager M, Behrendt H, Ring J, Krämer U: Prevalence of overweight and obesity in East and West German children in the decade after reunification: population- 
based series of cross-sectional studies. Evidence-based public health policy and practice 2008, 62(2):125130.

7. Moss A, Klenk J, Simon K, Thaiss H, Reinehr T, Wabitsch M: Declining prevalence rates for overweight and obesity in German children starting school. European Journal of Pediatrics 2012, 171(2):289-299.

8. Liu W, Schwertz R, Welker A, Welker J, Chen S, Dambach P, Marx MJEJoPH: Associations between BMI and visual impairment of $33 \mathbf{4 0 7}$ preschool children in Germany: a pooled cross-sectional study. 2021, 31(1):105-111.

9. Ministry of Education and cultural affairs in Baden-Württemberg: School Act for Baden-Württemberg (SchG) in the version of August 1, 1983. In. Edited by affairs MoEac. Baden-Württemberg Ministry of Social Affairs of Baden-Württemberg,; 2010.

10. Ministry of Social Affairs in Baden-Württemberg: Ordinance of the Ministry of Social Affairs for the implementation of school medical examinations as well as target group-specific examinations and measures in day care centers and schools (School Examination Ordinance) from December 8, 2011. In. Edited by Affairs MoS. Baden-Württemberg: Ministry of Social Affairs in Baden-Württemberg; 2011.

11. Ministry of Social Affairs in Baden-Württemberg: Public Health Service Act (Health Services Act ÖGDG) of December 17, 2015 1). In. Edited by Affairs MoS. Baden-Württemberg: Ministry of Social Affairs in Baden-Württemberg; 2015.

12. The WHO Child Growth Standards: BMI for

age, [https://www.who.int/childgrowth/standards/bmi_for_age/en/]

13. Schenk L, Bau A, Borde T, Butler J, Lampert T, Neuhauser H, Razum O, Weilandt C: A basic set of indicators for mapping migrant status. Recommendations for epidemiological practice. Bundesgesundheitsblatt, Gesundheitsforschung, Gesundheitsschutz 2006, 49(9):853-860.

14. Terrell GR, Scott DW: Variable kernel density estimation. The Annals of Statistics 1992:1236-1265.

15. Chen Y-C: A tutorial on kernel density estimation and recent advances. Biostatistics

Epidemiology 2017, 1(1):161-187.

16. Kromeyer-Hauschild $\mathrm{K}$, Zellner $\mathrm{K}$ : Trends in overweight and obesity and changes in the distribution of body mass index in schoolchildren of Jena, East Germany. European Journal of Clinical Nutrition 2007, 61(3):404-411.

17. Herpertz-Dahlmann B, Geller F, Böhle C, Khalil C, Trost-Brinkhues G, Ziegler A, Hebebrand J: Secular trends in body mass index measurements in preschool children from the City of Aachen, Germany. European Journal of Pediatrics 2003, 162(2):104-109. 
18. Ng M, Fleming T, Robinson M, Thomson B, Graetz N, Margono C, Mullany EC, Biryukov S, Abbafati C, Abera SF: Global, regional, and national prevalence of overweight and obesity in children and adults during 1980-2013: a systematic analysis for the Global Burden of Disease Study 2013. The lancet 2014, 384(9945):766-781.

19. Blüher S, Meigen C, Gausche R, Keller b, Pfäffle R, Sabin M, Werther G, Odeh R, Kiess W: Age-specific stabilization in obesity prevalence in German children: a cross-sectional study from 1999 to 2008. International journal of pediatric obesity 2011, 6(sup3):e199-206.

20. Blüher S, Meigen C, Gausche R, Keller b, Pfäffle R, Sabin M, Werther G, Odeh R, Kiess W: Age-specific stabilization in obesity prevalence in German children: a cross-sectional study from 1999 to 2008. International journal of pediatric obesity 2011, 6(sup3):e199-206.

21. Zhou Y, Walter U, Dreier M: Migration background and overweight prevalence in preschool children Public Health Forum 2019, 27(4):287-290.

22. Number of foreigners in German federal states in

2020 [https://www.statista.com/statistics/891288/foreigner-numbers-by-state-germany/]

23. Germany's National Sustainable Development Strategy [https://www.bundesregierung.de/bregen/issues/sustainability/germany-s-national-sustainable-development-strategy-354566]

24. Anderson PM, Butcher KE: Childhood obesity: trends and potential causes. The Future of children 2006, 16(1):19-45.

25. Janssen IJAP, Nutrition, Metabolism: Physical activity guidelines for children and youth. 2007, 32(S2E):S109-121.

26. Torkar G, Rejc A: Children's Play and Physical Activity in Traditional and Forest (Natural) Playgrounds. International Journal of Educational Methodology 2017, 3(1):25-30.

27. Sarwar S: Influence of parenting style on children's behaviour. Journal of Education Educational Development 2016, 3(2).

28. Carter D, Welch D: Parenting styles and children's behavior. Family relations 1981:191-195.

29. Apfelbacher CJ, Loerbroks A, Cairns J, Behrendt H, Ring J, Krämer U: Predictors of overweight and obesity in five to seven-year-old children in Germany: Results from cross-sectional studies. BMC Public Health 2008, 8(1):171.

30. Besharat Pour M, Bergström A, Bottai M, Kull I, Wickman M, Håkansson N, Wolk A, Moradi T: Effect of parental migration background on childhood nutrition, physical activity, and body mass index. Journal of obesity 2014, 2014. 
31. Hilpert M, Brockmeier K, Dordel S, Koch B, Weiß V, Ferrari N, Tokarski W, Graf C: Sociocultural influence on obesity and lifestyle in children: A study of daily activities, leisure time behavior, motor skills, and weight status. Obesity facts 2017, 10(3):168-178.

32. Vilar-Compte M, Bustamante AV, López-Olmedo N, Gaitán-Rossi P, Torres J, Peterson KE, Teruel G, Pérez-Escamilla R: Migration as a determinant of childhood obesity in the United States and Latin America. Obesity Reviews 2021, 22:e13240.

33. Levitt P: Social remittances: Migration driven local-level forms of cultural diffusion. International migration review 1998, 32(4):926-948.

34. Do LM, Tran TK, Eriksson B, Petzold M, Ascher H: Prevalence and incidence of overweight and obesity among Vietnamese preschool children: a longitudinal cohort study. BMC Pediatrics 2017, 17(1):150.

35. van Jaarsveld $\mathrm{CH}$, Gulliford MC: Childhood obesity trends from primary care electronic health records in England between 1994 and 2013: population-based cohort study. Archives of disease in childhood 2015, 100(3):214-219.

36. Organization WH: Obesity: preventing and managing the global epidemic: report of a WHO consultation on obesity, Geneva, 3-5 June 1997. In.: World Health Organization; 1998.

37. Dietz WH: Periods of Risk in Childhood for the Development of Adult Obesity - What Do We Need to Learn? The Journal of Nutrition 1997, 127(9):1884S-1886S.

38. Johnson SL, Birch LL: Parents' and children's adiposity and eating style. Pediatrics 1994, 94(5):653661.

\section{Figures}

Figure 1

Distribution change of body mass index among male (a) and female (b) preschool children.

Figure 2

The trend of overweight and obesity from 2013 to 2018

\section{Supplementary Files}


This is a list of supplementary files associated with this preprint. Click to download.

- Supplementaryfile.docx 